Boucetta Djahida

Imine Omar

http://dx.doi.org/10.21278/brod68107

ISSN 0007-215X

eISSN 1845-5859

\title{
IMPACT OF SOME GEOMETRICAL ASPECTS ON THE TANDEM CO-ROTATING PROPELLER HYDRODYNAMIC CHARACTERISTICS
}

UDC 629.5.024.71

Original scientific paper

\begin{abstract}
Summary

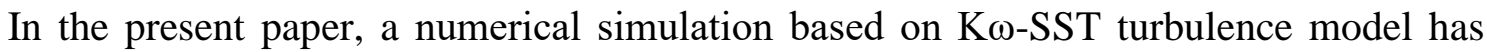
been carried out to determine the tandem propeller hydrodynamic characteristics in noncavitating viscous flow by using the commercial code Fluent. As the first step, the numerical approach has been applied to the case of single propeller and the comparison with experiment results was in a good agreement. Next, the effects of axial and angular displacement as well as the diameter ratio between the tandem propellers have been investigated. This part of the study reveals that the tandem with idem propeller diameters is strongly recommended to assure more advantages. Furthermore, the tandem geometry corresponding to the axial displacement equal to $0.6 \mathrm{D}$ seems to be the best configuration and the open water performances remain almost unchanged with the variation of angular displacement. On the other hand, details of the mutual interaction between tandem propellers were also given by showing pressure contours, streamlines and thrust coefficient. Globally, this study illustrates the advantages of replacing single propellers by tandem solution.
\end{abstract}

Key words: $\quad$ marine propeller; tandem propellers; non-cavitating viscous flow; RANS method; hydrodynamic characteristics.

\section{Introduction}

Co-rotating tandem propellers can be described as a pair of conventional propellers fitted on the same shaft in series and rotating in the same direction. The design of these propellers is based on the same requirements and assumptions that are used in the case of single propellers [1]. However, it requires taking into account the effects of mutual hydrodynamic interaction between the fore and aft propeller as well as the distribution of the hydrodynamic loading between both propellers [2-3]. The solution of propellers in tandem configuration is less expensive and complex than contra-rotating and twin screw devices.

Practically, the tendency to improve propulsive efficiency with increasing propeller power absorption and the consequent risk of cavitation that provokes means that the role of the conventional propeller is almost restricted in some applications [4-5]. The tandem can 
then be regarded as a practical promise of extending this difficult operating range. The application of this type of propulsion can be helpful when a very high power has to be absorbed by a single propeller but with restriction about the amount of diameter. Indeed, for a given thrust, the use of tandem permits advantageously to double effective blade area and decreases significantly the propellers diameter [6].

In this context, many experimental researches [7-8] were conducted to show the performances of the tandem propeller and thus to mention the best conditions for their good usage in the naval propulsion. Tests revealed that under some conditions efficiencies were almost higher with tandem than with the corresponding single propellers and more favorable conditions were obtained for the occurrence of cavitation. Qin Sun et al. [9] investigate the hydrodynamic characteristics of tandem propellers and demonstrate their range of application to ships. A simplified practical design approach has been proposed which, together with the experiments, has been helpful in assessing the importance of some propeller design parameters. Open water design charts have been produced by testing two model tandem propellers with an axial relative position less than 0.3 . The design approach has been validated with many experiment tests on small vessels and very high powered ships fitted with tandem propeller. The obtained results confirm that propulsive power, bollard pull and vibration levels were better than those of conventional propeller. The efficiency of two classes of tandem, the CLB4-40-2 and CLB4-55-2 tandem propellers, was measured experimentally in [10]. The authors explore the important aspects of the tandem including pitch ratio, diameter ratio and pitch distribution. Tandem configuration can be often encountered in the pod device [11-12-13]. Authors in [14] measured experimentally the thrust and torque of pod propellers in tandem configuration. The advance coefficient was taken up to 1.08 where the angular displacement is within the range of 0 to $90^{\circ}$. Results show that the thrust decreases with increasing steering angle and torque increases when the steering angle increases.

Application of theoretical approaches can be found in the work of Koronowicz et al. [15-16]. They present a computer system for the complete design of tandem co-rotating propellers. Based on the vortex theory, the determination of the hydrodynamic loading division between the forward and the aft propeller was evaluated. This approach is sufficiently accurate for the calculation of velocities induced on propeller blades and the program facilitates the process of the tandem co-rotating propeller design. Later in [17], a procedure for calculating the self and mutually induced velocities of two propeller system (tandem and contra rotating propellers) was developed. The lifting line theory is applied for the calculation of the velocity field and the circulation theory is used for the calculation of the induced velocities. Qin Sun [18] presents a simplified theoretical method to design tandem propellers by using lifting line theory and analyses of induced velocity variation between the two propellers were investigated. The tandem propeller would have been more efficient as relative axial spacing is smaller according to various studies [9-19] and the optimum values are situated between 0.2 and 0.25 . A FORTRAN program to calculate the three-dimensional unsteady viscous flow around tandem propellers can be found in [20]. Hydrodynamic parameters of the tandem propellers such as thrust coefficient, torque coefficient and velocity distribution are represented in open water performance curves. In the same context, recent works investigate the possibility of the CFD application to the tandem propeller performance evaluation and optimization [21-22-23]. Numerical simulation results are compared with experimental values to verify the accuracy of the CFD methods to predict the viscous flow around tandem propellers [24-25]. Furthermore, numerical simulation of the flow around DTRC 4119 paddle in a non-uniform is presented in [26] to estimate the unsteady hydrodynamic characteristics. The comparison of numerical results with the experimental 
data, verifies the feasibility of the CFD method. The analysis of open water performances of a paddle B propeller series has been presented using Reynolds-Averaged Navier-Stokes (RANS) approach [27] and testing also several turbulence models for the flow around tandem propellers. Results confirm that the propulsive efficiency is significantly improved by a tandem system.

The present work deals with a numerical investigation on the non-cavitating viscous flow around co-rotating tandem using RANS approach. This study explores the hydrodynamic behavior of co-rotating tandems of which the distance between propellers is in the range of $0.2 \mathrm{D}$ to $0.8 \mathrm{D}$. Effects of angular position as well as diameter ratio between both tandem propellers are also investigated. In this study, the numerical simulation is applied only to the case of open water tests and the analysis of tandem performances is presented. Calculations

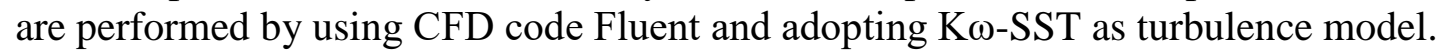

\section{Numerical methods}

\subsection{Governing equations}

The governing equations of the turbulent viscous flow around marine propeller are written as follows:

$$
\begin{aligned}
& \frac{\partial \rho}{\partial t}+\frac{\partial}{\partial x_{i}}\left(\rho u_{i}\right)=0 \\
& \frac{\partial}{\partial t}\left(\rho u_{i}\right)+\frac{\partial}{\partial x_{j}}\left(\rho u_{i} u_{j}\right)=\rho g_{i}-\frac{\partial p}{\partial x_{i}}+\frac{\partial x_{i j}}{\partial x_{j}}
\end{aligned}
$$

Where $u_{i}$ and $u_{j}$ are the velocity components of water, $\rho$ is the density, $P$ is the pressure, and $\tau$ is the shear stress tensor. The Reynolds stress must be modeled to close the governing equation by using an appropriate turbulence model.

\subsection{Characteristics of marine propellers}

The effectiveness of the propulsion system is strongly dependent on thrust force, torque of propeller and its efficiency. Therefore, to evaluate the marine propeller hydrodynamic characteristics is to plot the coefficients $\mathrm{K}_{\mathrm{T}}, \mathrm{K}_{\mathrm{Q}}, \eta_{0}$ versus the advance coefficient $\mathrm{J}$. The tandem propeller performance is estimated by calculating the efficiency $\eta_{0}$ given in (3).

$$
\eta_{0}=\frac{\mathrm{K}_{\mathrm{T}_{\text {Total }}}}{\mathrm{K}_{\mathrm{Q}_{\text {Total }}}} \times \frac{\mathrm{I}}{2 \pi}
$$

$\mathrm{J}$ is the advance ratio which can be expressed as follows:

$$
\mathrm{J}=\frac{\mathrm{v}_{\text {inlet }}}{\mathrm{n} \cdot \mathrm{D}}
$$

Where: Vinlet is the uniform inflow velocity; $\mathrm{D}$ the diameter of the fore propeller and $\mathrm{n}$ the rotational speed of the propeller.

The open water efficiency $\eta_{0}$ is established for a propeller working in a homogeneous flow without any ship hull. Where $\mathrm{K}_{\mathrm{TTota}}$ is the total thrust coefficient and $\mathrm{K}_{\mathrm{QTotal}}$ is the total torque coefficient. Both coefficients are calculated respectively:

$$
\begin{gathered}
\mathrm{K}_{\mathrm{T}_{\text {Total }}}=\frac{\mathrm{T}_{\text {Fore }}+\mathrm{T}_{\text {Aft }}}{\mathrm{P}^{-} \mathrm{n}^{2} \cdot \mathrm{D}_{\text {Fore }}{ }^{4}} \\
\mathrm{~K}_{\mathrm{Q}_{\text {Total }}}=\frac{\mathrm{Q}_{\mathrm{Fore}}+\mathrm{Q}_{\text {Aft }}}{\mathrm{P}^{-} \mathrm{n}^{2} \cdot \mathrm{D}_{\text {Fore }}{ }^{5}}
\end{gathered}
$$




\subsection{Geometric modeling}

The tandem propeller used for calculation is a dual of conventional Seiun Maru propeller model, with blade numbers $(5+5)$ and blade expanded area ratios of $(0.65+0.65)$. The tandem geometries tested have a pitch ratio difference between the aft and fore propeller of 0.2 according to the study presented in [9]. The Seiun Maru propeller model is a Japanese series with the modified NACA 66 section and had taken the name of Seiun Maru ship. The detailed measurements are reported in [27] and the main parameters of the propeller are summarized in Table 1. Propeller design in tandem is based on the same requirements and assumptions that are used in the design of conventional propellers. In this paper, the nondimensional blade geometry data of the propeller is presented in Table 2. This data was converted into coordinate points to generate the surface model of propeller by using a FORTRAN Program. The domains containing respectively the aft and the fore propellers were created individually and then assembled by mean of interfaces. A solid model of the propeller was created in Gambit as shown in Figure 1.

Table 1 Principal particulars of Seiun Maru conventional propeller

\begin{tabular}{|l|l|}
\hline Model name & Seiun Maru \\
\hline Number of blades & 5 \\
\hline Diameter $(\mathrm{m})$ & 0.360 \\
\hline Boss ratio & 0.1972 \\
\hline Pitch ratio at $0.7 \mathrm{R}$ & 0.950 \\
\hline Expanded area ratio & 0.650 \\
\hline Skew $(\mathrm{m})$ & 0.183 \\
\hline Rake $\left(^{\circ}\right)$ & 6.0 \\
\hline
\end{tabular}

Table 2 Blade characteristics of the Seiun Maru propeller model [28]

\begin{tabular}{|l|l|l|l|r|r|r|}
\hline $\mathbf{r} / \mathbf{R}$ & $\mathbf{r}(\mathbf{m})$ & $\mathbf{C}(\mathbf{m})$ & $\mathbf{P} / \mathbf{D}$ & $\mathbf{P}(\mathbf{m})$ & Rake $(\mathbf{m})$ & Skew $(\mathbf{m})$ \\
\hline 0.197 & 0.355 & 0.706 & 0.95 & 3.420 & 0.0378 & -0.056 \\
0.3 & 0.540 & 0.824 & 0.95 & 3.420 & 0.0568 & -0.057 \\
0.4 & 0.720 & 0.924 & 0.95 & 3.420 & 0.0757 & -0.051 \\
0.5 & 0.900 & 1.001 & 0.95 & 3.420 & 0.0946 & -0.0385 \\
0.6 & 1.080 & 1.051 & 0.95 & 3.420 & 0.1135 & -0.0175 \\
0.7 & 1.260 & 1.057 & 0.95 & 3.420 & 0.1324 & 0.0165 \\
0.8 & 1.440 & 0.986 & 0.95 & 3.420 & 0.1514 & 0.063 \\
0.9 & 1.620 & 0.794 & 0.95 & 3.420 & 0.1703 & 0.118 \\
0.95 & 1.710 & 0.600 & 0.95 & 3.420 & 0.1797 & 0.154 \\
1 & 1.800 & 0.001 & 0.95 & 3.420 & 0.1892 & 0.183 \\
\hline
\end{tabular}

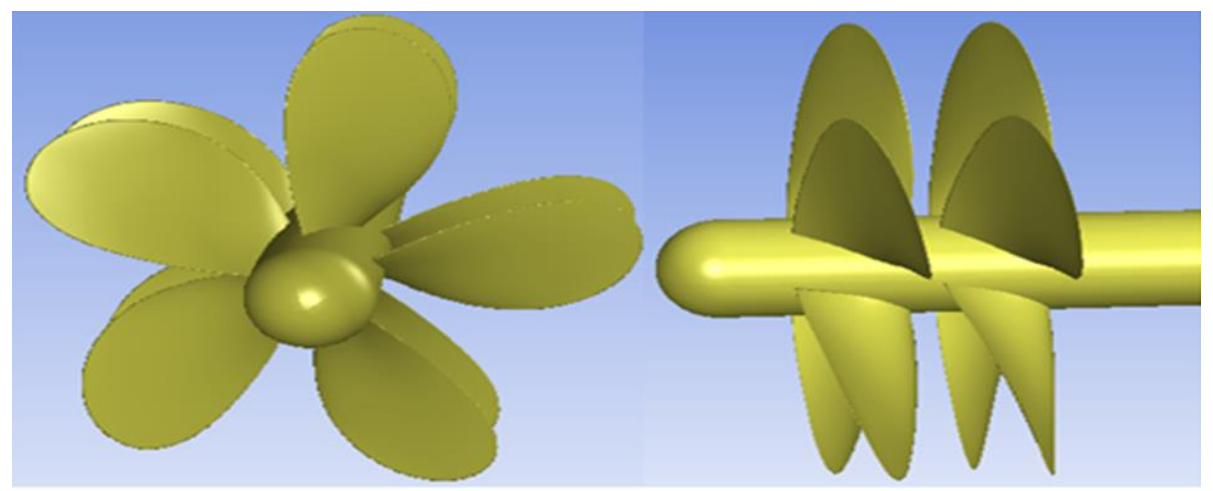

Fig. 1 Perspective view of tandem propeller blades 


\subsection{Grid generation}

The computational domain was divided into two blocks; the first block surrounds the fore propeller blade and the second block envelopes the rear blade. The output of the first block and the input of second become periodical interfaces, Figure 2. Due to the complexity of marine propeller geometry, unstructured tetrahedral mesh has been adopted. Taking into account that the flow is circumferentially periodic, only one angular sector of $72^{\circ}$ containing one blade was modeled. The solution domain represents $1 / 5$ of a cylinder with its inlet located at $1.5 \mathrm{D}$ upstream, and its outlet located at 3.5D downstream of propeller plane. In the radial direction, the domain was considered up to a distance of 1.4D from the axis of the hub. The proportions of the domain were chosen according to the studies cited in [29]. Figure 3 shows the computational domain and boundary conditions used for the simulation. Different zones with refined meshes have been introduced around the cross section of the blade at the hub intersection and near the blade tip. A mesh refinement zone is defined near the propeller surface in order to capture the high gradients in the flow. The mesh was generated in such a way that cell sizes near the blade wall were small and increased progressively towards outer boundary. To resolve the turbulent boundary layer on the blade surfaces, TGrid code has been used. Five layers of prismatic cells were growing from the blade and hub surface where the first cell height was $0.00001 \mathrm{D}$ and the growth ratio of the layers was 1.1 in order to provide wall $y+<1$. Figure 4 shows the grid over the entire blade and hub propeller. Finally, all the calculation zones and domain, except for the boundary layer, are meshed by tetrahedral meshes as shown in Figure 5. Three meshes were generated to test the sensitivity of the solution to the mesh size and computation was made for the open water performance prediction of the propeller model as resume Table 3.

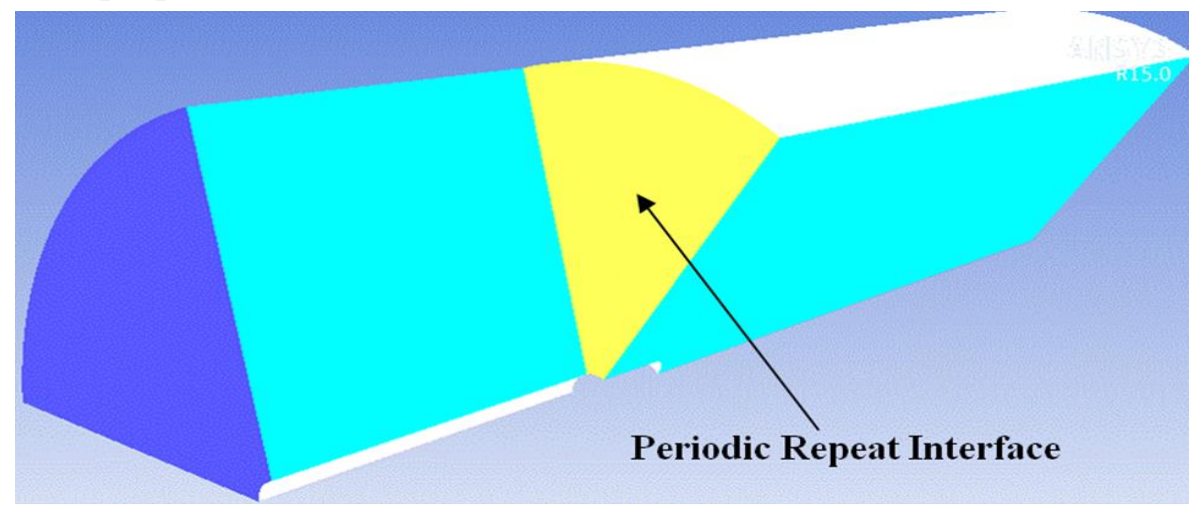

Fig. 2 Computational domain with periodical interfaces

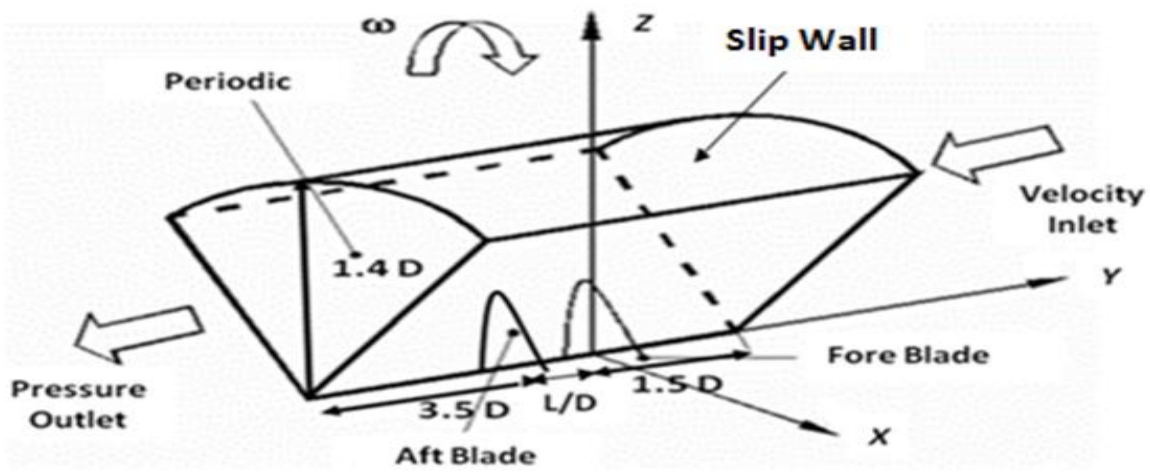

Fig. 3 Computational domain and boundary conditions 


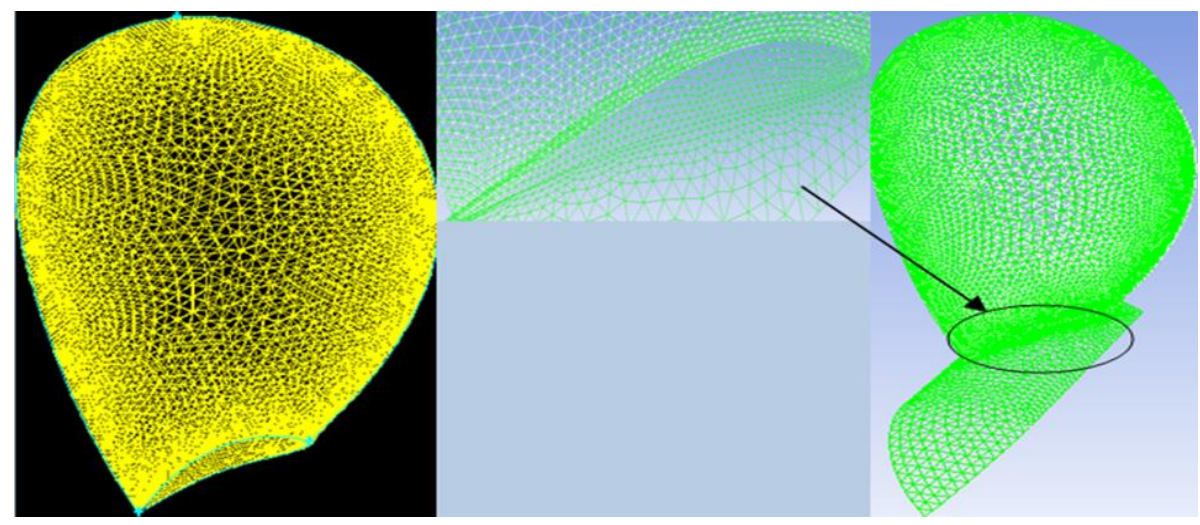

Fig. 4 Mesh on surface blade and boundary layer

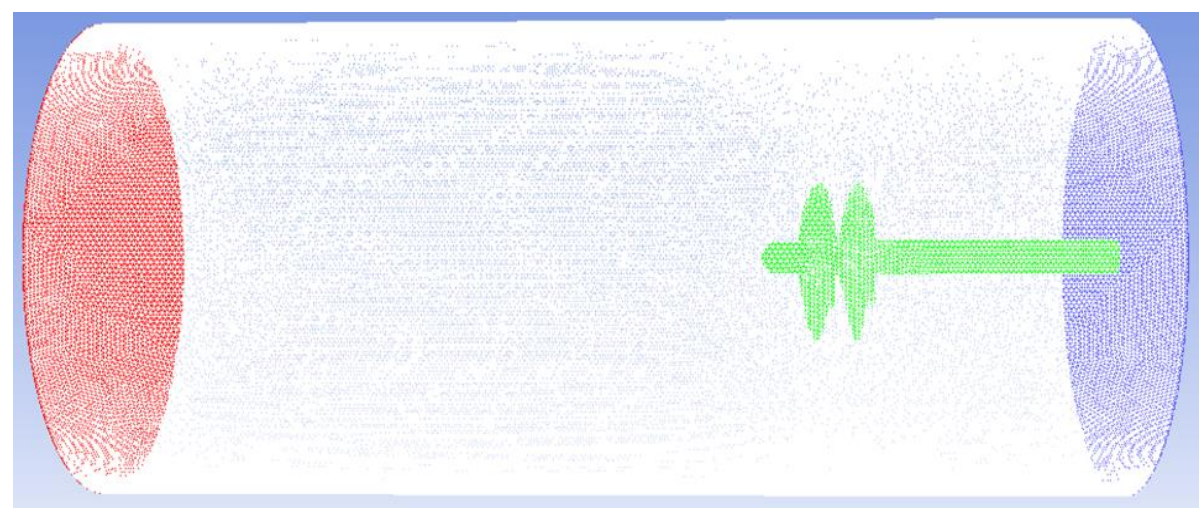

Fig. 5 Grid over the computational domain

\subsection{Solver settings}

In this section, the numerical approach used to describe the non-cavitating viscous flow around co-rotating tandem is presented. The water in the computational domain is assumed to be an incompressible flow and the moving reference frame option is applied to the entire fluid domain. For all calculations, the rotational speed of propellers is kept constant and equal to $\mathrm{n}=217.8 \mathrm{~min}^{-1}$ giving a Reynolds number, based on the propeller diameter, equal to $\mathrm{Re}=5.8$ $10^{5}$. The inlet velocity is changing in such a way to obtain the advance coefficient between $\mathrm{J}=0.3$ and $\mathrm{J}=1.1$. Pressure outlet boundary conditions are adopted with the option of radial equilibrium distribution. The wall forming the propeller blade and hub are considered as a non-slip boundary condition. The far boundary in the radial direction is taken as inviscid wall. The SST (Shear Stress Transport) k- $\omega$ turbulence model is employed to calculate Reynolds stresses in the RANS equations [30]. The SIMPLE algorithm has been adopted for the velocity-pressure coupling and the discretization schemes have been all in the second order. The convergence of the calculations is controlled from the evolution of the residues and the coefficients $\mathrm{K}_{\mathrm{T}}$ and $\mathrm{K}_{\mathrm{Q}}$.

\section{Results and discussions}

To validate the present numerical model, calculations have been performed on the Seiun- Maru propeller which experimental data is available [31]. In this case, it is assumed that the flow around the propeller is non-cavitant where the rotational speed was maintained constant and equal to $217.8 \mathrm{~min}^{-1}$. The calculations have been performed at $\mathrm{J}=0.8$ by trying three tetrahedral grids where the number of cells and the resulting $\mathrm{y}^{+}$are displayed in Table 3 . 
Table 4 compares the computed thrust and torque coefficients on the three grids with the experimental values (EXP). It is noted that the error in $\mathrm{K}_{\mathrm{T}}$ and $\mathrm{K}_{\mathrm{Q}}$ decreases as the grid is refined. So the fine grid is used in the following numerical simulation. Under different advance coefficients, results of open water tests are represented in terms of thrust, torque and efficiency coefficients, Figure 6. Globally, good agreement is observed for all coefficients due probably to the good mesh quality obtained particularly near the walls as it is shown in Figure 7. However, a small discrepancy is observed especially for $\mathrm{K}_{\mathrm{Q}}$. This tendency seems to be common in most of the RANS CFD simulation for marine propellers [32-35].

Table 3 Grid sizes and $\mathrm{y}^{+}$values of tested propeller

\begin{tabular}{|l|l|c|l|}
\hline Grid & Element type & Number of cells & $\mathbf{Y}^{+}$ \\
\hline Coarse & Tetrahedral & 523881 & 200 \\
\hline Medium & Tetrahedral & 925513 & 52 \\
\hline Fine & Tetrahedral & 1417642 & 0.322 \\
\hline
\end{tabular}

Table 4 Computed $\mathrm{K}_{\mathrm{T}}$ and $10 \mathrm{~K}_{\mathrm{Q}}$ of tested propeller at $\mathrm{J}=0.8$

\begin{tabular}{|l|l|l|l|l|l|l|}
\hline Grid & $\begin{array}{l}\mathbf{K}_{\mathbf{T}} \\
\text { RANS }\end{array}$ & $\begin{array}{l}\mathbf{K}_{\mathbf{T}} \\
\text { EXP }\end{array}$ & $\begin{array}{l}\text { Error in } \\
\mathbf{K}_{\mathbf{T}} \%\end{array}$ & $\begin{array}{l}\mathbf{1 0 K}_{\mathbf{Q}} \\
\mathbf{R A N S}\end{array}$ & $\begin{array}{l}\mathbf{1 0} \mathbf{K}_{\mathbf{Q}} \\
\mathbf{E X P}\end{array}$ & $\begin{array}{l}\text { Error in } \\
\mathbf{1 0 ~ K}_{\mathbf{Q}} \%\end{array}$ \\
\hline Coarse & 0.138 & 0.122 & 12.46 & 0.257 & 0.216 & 18.98 \\
\hline Medium & 0.134 & 0.122 & 9.53 & 0.246 & 0.216 & 13.90 \\
\hline Fine & 0.132 & 0.122 & 6.61 & 0.232 & 0.216 & 3.38 \\
\hline
\end{tabular}

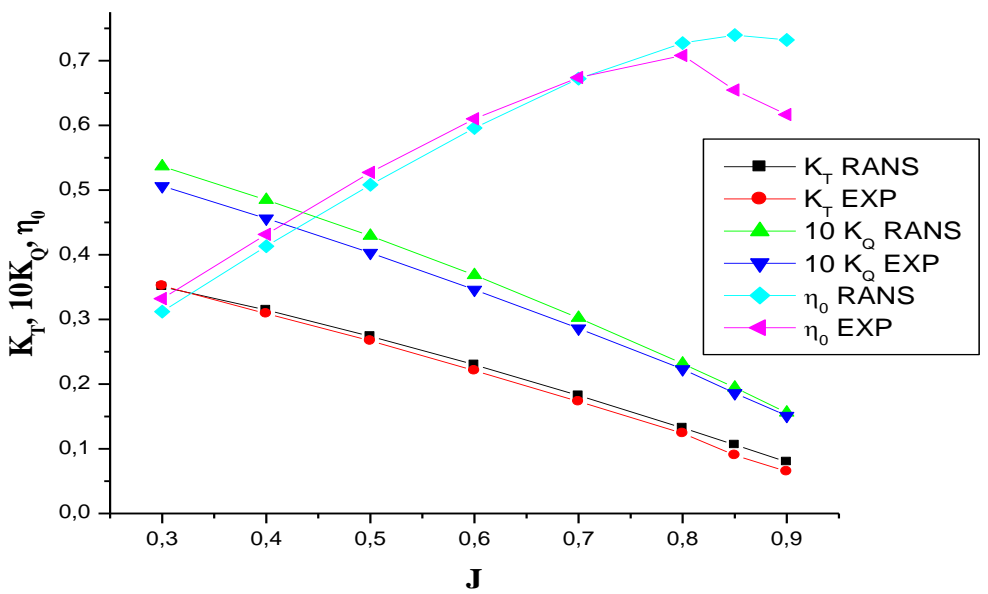

Fig. 6 Open water performances of conventional propeller model

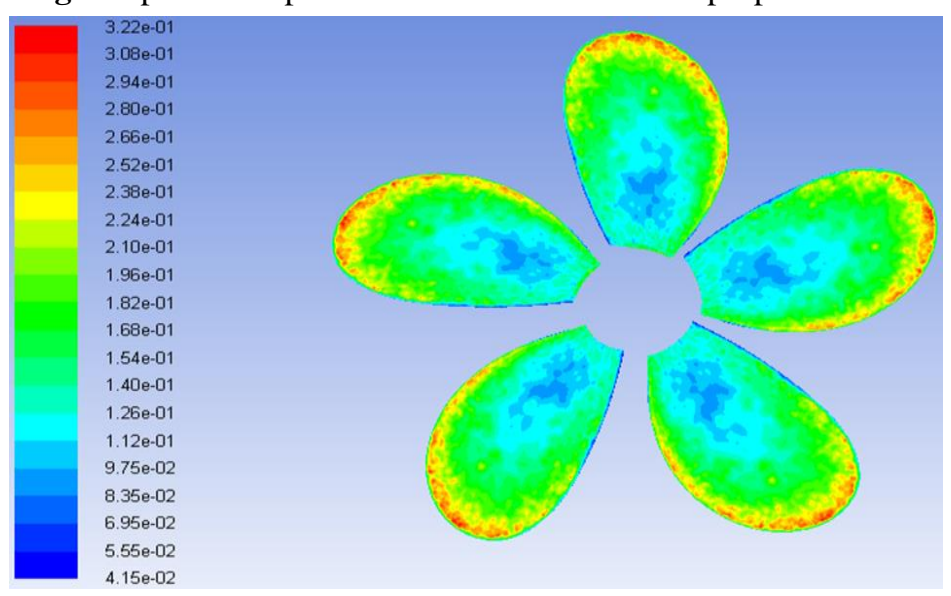

Fig. 7 Contours of wall $\mathrm{y}^{+}$at $\mathrm{J}=0.8$ 
In order to obtain an optimum configuration in tandem, a parametrical study is carried out by varying the axial and angular relative position as well as the diameter ratio between the aft and the forward propeller.

First, tandem configuration with identical propellers is tested for different values of relative axial distance (L/D) namely: $0,0.2,0.3,0.4,0.4,0.5,0.6,0.7$ and 0.8 . The configuration $\mathrm{L} / \mathrm{D}=0$ which corresponds to the single Seiun Maru propeller is taken as reference for the comparison. Figure 8 shows the evolution of $K_{T}, K_{Q}$, and $\eta_{0}$ versus $J$ for the adopted models.

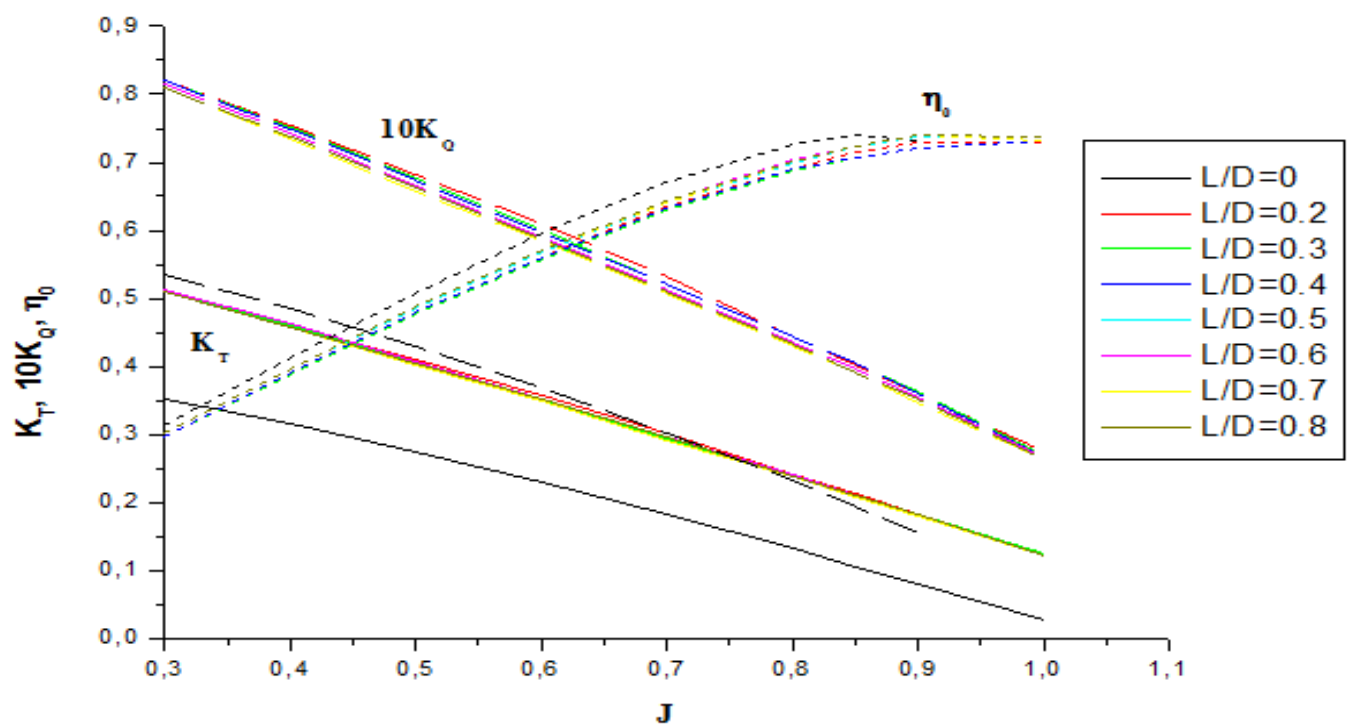

Fig. 8 Tandem hydrodynamic characteristics for different axial displacement

It is observed that the interaction between the two propellers causes an increase in $\mathrm{K}_{\mathrm{T}}$ and $\mathrm{K}_{\mathrm{Q}}$ coefficients with a rate between 40 and $120 \%$. In this context, Figure 9 shows an example of pressure distributions for the single propeller and tandem identical diameter propellers with $L / D=0.6$. It is observed an existence of large depression zone on fore propeller back side and reciprocally large pressure zone in the face side similar to the single propeller. As it is shown, the displayed distributions confirm the moderately positive contribution of the aft propeller in thrust where the lower pressure region is localized in the upper part of the blade. Table 5 illustrates the details of thrust contribution by propeller for the configuration mentioned below.

A- $\quad$ Single propeller

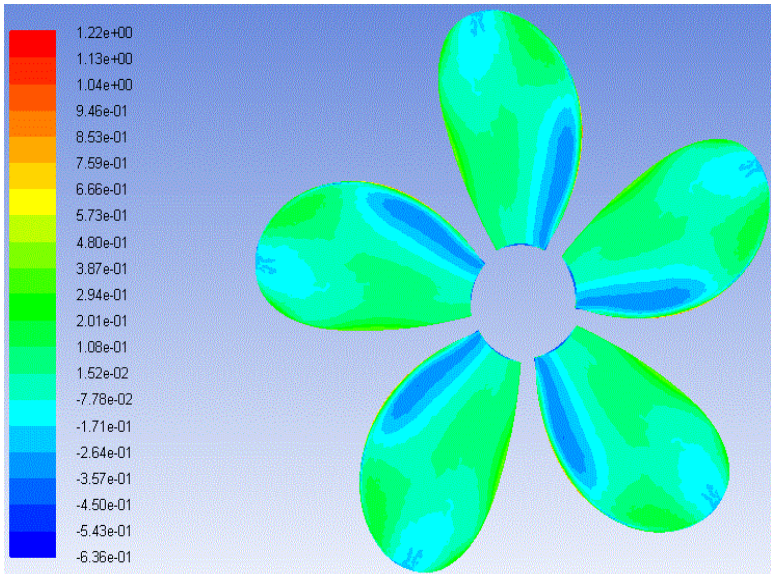

Face side (Intrados)

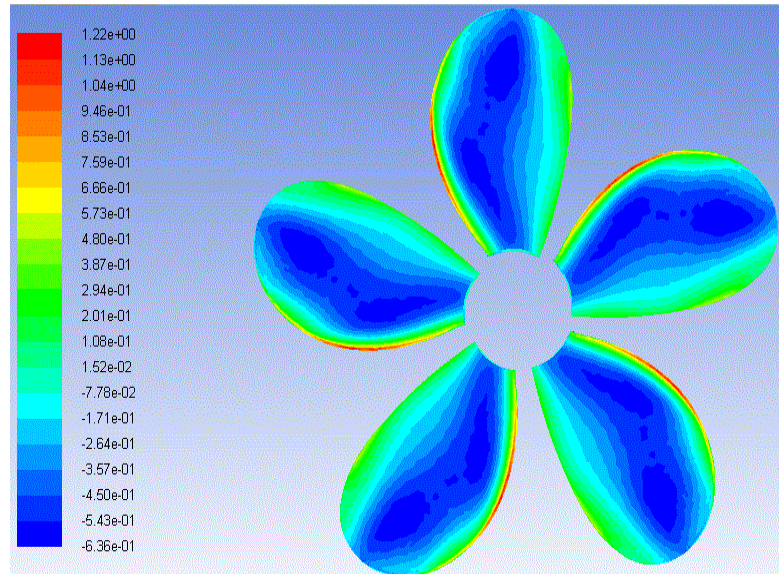

Back side (Extrados) 


\section{B- $\quad$ Tandem Fore propeller $\mathrm{L} / \mathrm{D}=0.6$}

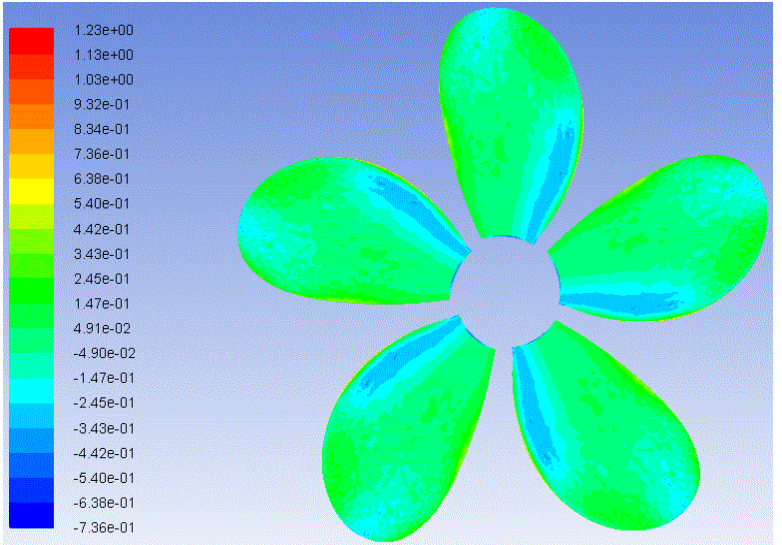

Face side (Intrados)

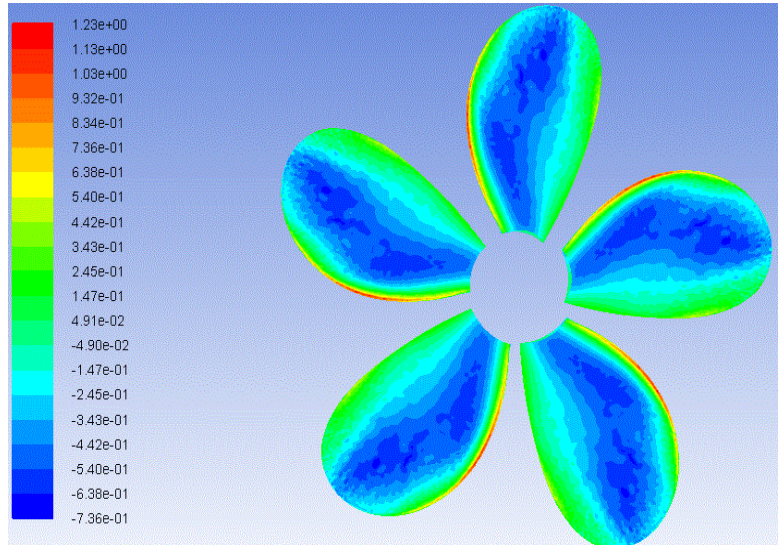

Back side (Extrados)

C- $\quad$ Tandem Aft propeller $\mathrm{L} / \mathrm{D}=0.6$

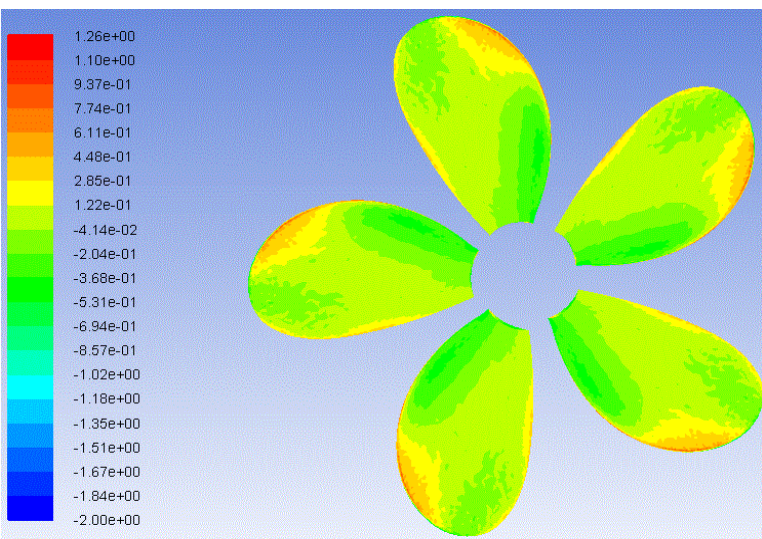

Face side (Intrados)

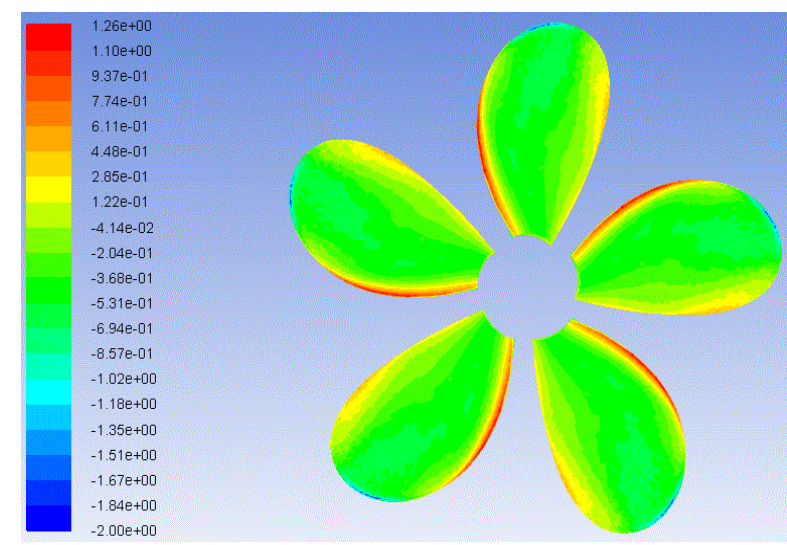

Back side (Extrados)

Fig. 9 Distribution of pressure coefficient contours for the single and tandem propeller

Table 5 Thrust coefficient $\left(\mathrm{K}_{\mathrm{T}}\right)$ for the tandem configuration $\mathrm{L} / \mathrm{D}=0.6$

\begin{tabular}{|c|c|c|c|c|}
\hline $\begin{array}{c}\text { Propeller } \\
\mathbf{J}\end{array}$ & Single & Fore & Aft & Tandem \\
\hline 0.3 & 0.3565 & 0.3770 & 0.1370 & 0.5140 \\
\hline 0.4 & 0.3195 & 0.3360 & 0.1260 & 0.4620 \\
\hline 0.5 & 0.2790 & 0.2915 & 0.1165 & 0.4080 \\
\hline 0.6 & 0.2350 & 0.2440 & 0.1085 & 0.3525 \\
\hline 0.7 & 0.1875 & 0.1940 & 0.1025 & 0.2965 \\
\hline 0.8 & 0.1365 & 0.1405 & 0.0990 & 0.2400 \\
\hline 0.85 & 0.1095 & 0.1135 & 0.0980 & 0.2115 \\
\hline 0.9 & 0.0805 & 0.0855 & 0.0975 & 0.1830 \\
\hline
\end{tabular}

Although the analysis of thrust curves shows that all configurations exhibit approximately the same $\mathrm{K}_{\mathrm{T}}$, the propeller with $\mathrm{L} / \mathrm{D}=0.6$ appears to be the best. For all configurations, torque evolution curves are slightly distinct. It seems that the highest values of $\mathrm{K}_{\mathrm{Q}}$ correspond to the configuration $\mathrm{L} / \mathrm{D}=0.2$, therefore this causes a decrease in the propeller efficiency, while the geometries $\mathrm{L} / \mathrm{D}=0.6, \mathrm{~L} / \mathrm{D}=0.7$ and $\mathrm{L} / \mathrm{D}=0.8$ present almost the lowest $\mathrm{K}_{\mathrm{Q}}$ among others. 
Globally, the efficiency curves show that the single propeller is slightly better than the tandem in the overall interval of $\mathbf{J}$ except for the high values. It is noticed also that the maximum value of $\eta_{0}$ is approximately the same for all compared propellers. Moreover, the highest $\eta_{0}$ for the single propeller corresponds to a lower advance parameter compared to the tandem. In the tandem efficiency graphs, it is observed that the curve near the maximum has a plate shape. Therefore, the tandem propeller conserves advantageously the maximum $\eta_{0}$ for an interval $\mathrm{J} \epsilon[0.9,1]$.

Table 6 gives the maximum efficiency value versus corresponding advance coefficient for all tested configurations. It appears clearly that the tandem geometry corresponding to $\mathrm{L} / \mathrm{D}=0.6$ can be more highly placed among other geometries. In the experimental study mentioned in the reference [9], it is indicated that the axial displacement $\mathrm{L} / \mathrm{D}=0.2$ is the most appropriate for a tandem propellers. However, in this study the tested configurations were limited to $\mathrm{L} / \mathrm{D}=0.3$.

Table 6 Evolution of the efficiency $\left(\eta_{0}\right)$ for different axial displacement values and different $\mathbf{J}$

\begin{tabular}{|l|l|l|l|l|l|l|l|l|}
\hline $\mathbf{J}$ & $\mathbf{L} / \mathbf{D = 0}$ & $\mathbf{L} / \mathbf{D = 0 . 2}$ & $\mathbf{L} / \mathbf{D = 0 . 3}$ & $\mathbf{L} / \mathbf{D = 0 . 4}$ & $\mathbf{L} / \mathbf{D = 0 . 5}$ & $\mathbf{L} / \mathbf{D = 0 . 6}$ & $\mathbf{L} / \mathbf{D = 0 . 7}$ & $\mathbf{L} / \mathbf{D = 0 . 8}$ \\
\hline 0.3 & 0.312 & 0.297 & 0.296 & 0.297 & 0.300 & 0.301 & 0.301 & 0.300 \\
\hline 0.4 & 0.413 & 0.389 & 0.389 & 0.391 & 0.395 & 0.397 & 0.396 & 0.396 \\
\hline 0.5 & 0.508 & 0.477 & 0.477 & 0.480 & 0.485 & 0.487 & 0.487 & 0.487 \\
\hline 0.6 & 0.595 & 0.560 & 0.558 & 0.561 & 0.569 & 0.570 & 0.569 & 0.569 \\
\hline 0.7 & 0.672 & 0.634 & 0.629 & 0.632 & 0.641 & 0.644 & 0.640 & 0.643 \\
\hline 0.8 & 0.727 & 0.691 & 0.687 & 0.689 & 0.670 & 0.701 & 0.700 & 0.700 \\
\hline 0.85 & 0.739 & 0.714 & 0.708 & 0.708 & 0.724 & 0.724 & 0.723 & 0.723 \\
\hline 0.9 & 0.732 & 0.730 & 0.720 & 0.721 & 0.738 & 0.742 & 0.740 & 0.740 \\
\hline 1 & 0.607 & 0.728 & 0.732 & 0.732 & 0.736 & 0.736 & 0.731 & 0.736 \\
\hline
\end{tabular}

In order to test the effect of relative angular position between tandem propellers, numerical simulations have been carried out on the previous configurations. As is mentioned in [9],the optimum angular displacement $(\theta)$ of the aft propeller to the forward propeller is the one which allows the vortex sheets of the forward propeller to pass midway between the after propeller blades. According to the circulation theory the optimum angular spacing is approximated by using the above equation for each axial displacement as it is summarized in Table 7.

$$
\theta=\frac{(\mathrm{L} / \mathrm{D})}{(\mathrm{P} / \mathrm{D})} \times 360 \pm\left(180^{\circ} / \mathrm{z}\right)
$$

Table 7 Optimum angular positions for each axial displacement

\begin{tabular}{|l|l|l|l|l|l|l|l|}
\hline $\mathbf{L} / \mathbf{D}$ & 0.2 & 0.3 & 0.4 & 0.5 & 0.6 & 0.7 & 0.8 \\
\hline $\boldsymbol{\theta}$ & 39 & 41 & 43 & 45 & 47 & 49 & 51 \\
\hline
\end{tabular}

Figure 10 shows the hydrodynamic characteristics of the tested tandems. The exam of $\mathrm{K}_{\mathrm{T}}$ and $\mathrm{K}_{\mathrm{Q}}$ curves confirms an increase in thrust and torque for all tandem geometries compared to the single propeller. However, the propeller with $\mathrm{L} / \mathrm{D}=0.8$ exhibits the least increase which reduces probably the propeller hydrodynamic characteristics. The efficiency graphs illustrate the tandem performances compared to the single propeller. It appears that the choice of tandem solution remains less attractive excepting for $\mathbf{J}$ corresponding to maximum efficiency. Among the tested tandems, $\mathrm{L} / \mathrm{D}=0.6$ stays the best design followed by $\mathrm{L} / \mathrm{D}=0.7$ and $\mathrm{L} / \mathrm{D}=0.2$. 


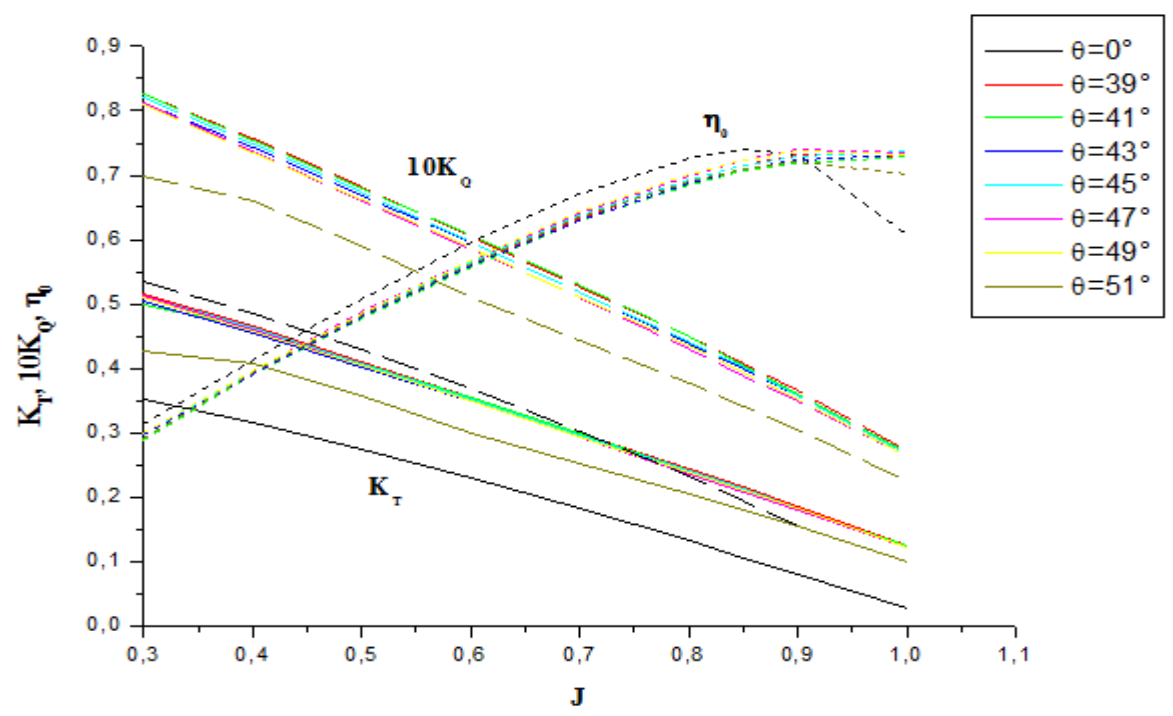

Fig. 10 Tandem hydrodynamic characteristics for optimum angular position

It is interesting to examine the tandem hydrodynamic characteristic behavior by varying the angular displacement between aft and fore propeller. For this, the $\mathrm{L} / \mathrm{D}=0.6$ configuration was chosen with six angular values: $0^{\circ}, 12^{\circ}, 24^{\circ}, 36^{\circ}, 48^{\circ}$ and $60^{\circ}$. Figure 11 shows the evolution of $\eta_{0}$ for the studied configurations. It is noticed for this configuration that the variation of angular displacement doesn't bring an improvement on the tandem's performances.

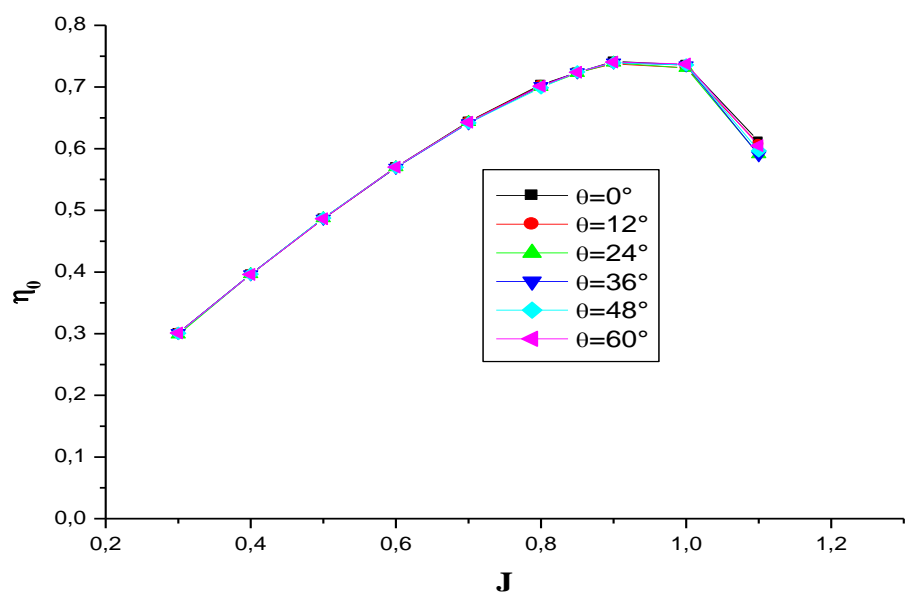

Fig. 11 Comparison of the calculated efficiency $\left(\eta_{0}\right)$ between different angular positions

For the last test, the effect of difference between the aft and fore propeller diameter expressed as a ratio $\left(\mathrm{D}_{\mathrm{Aft}} / \mathrm{D}_{\text {Fore }}\right)$ was studied. The case of $\mathrm{L} / \mathrm{D}=0.6$ was taken as model by adopting four ratios namely: $0,0.5,0.75$ and 1 . The values 0 and 1 correspond respectively to the single propeller and the tandem with identical propeller diameters. Figure 12 shows the evolution of $\mathrm{K}_{\mathrm{T}}, \mathrm{K}_{\mathrm{Q}}$ and $\eta_{0}$ for the configurations mentioned above. It can be seen that the tandem with identical diameter propellers provide the best thrust. Furthermore 0.5 and 0.75 configurations give approximately idem thrust. However, their values are less than single propeller $\mathrm{K}_{\mathrm{T}}$. This unexpected result is due to the negative thrust contribution of the aft propeller as shown in Table 8 for the case of $\mathrm{J}=0.9$ and confirmed by the pressure contours on the aft propeller, Figure 13. 
From $\mathrm{K}_{\mathrm{Q}}$ curves, the cases related to 0.5 and 0.75 ratio produce about the same torque but it remains lower than the single propeller $\mathrm{K}_{\mathrm{Q}}$. This is obviously due to the interaction between the tandem propellers which outcomes in the creation of opposed torques on tandem propellers. It is noticed that the maximum efficiency decreases by decreasing the diameters ratio. The tandem with identical diameter propellers exhibits the greatest efficiency.

Table 8 Propeller thrust contribution

\begin{tabular}{|l|c|c|c|}
\hline & Fore propeller & Aft propeller & Tandem propeller \\
\hline$\left(\mathbf{D}_{\text {Aft }} / \mathbf{D}_{\text {Fore }}\right)=\mathbf{0 . 5}$ & 0.0890 & -0.0435 & 0.0453 \\
\hline$\left(\mathbf{D}_{\text {Aft }} / \mathbf{D}_{\text {Fore }}\right)=\mathbf{0 . 7 5}$ & 0.1965 & -0.0295 & 0.0590 \\
\hline$\left(\mathbf{D}_{\text {Aft }} / \mathbf{D}_{\text {Fore }}\right)=\mathbf{1}$ & 0.0855 & 0.0943 & 0.1800 \\
\hline
\end{tabular}

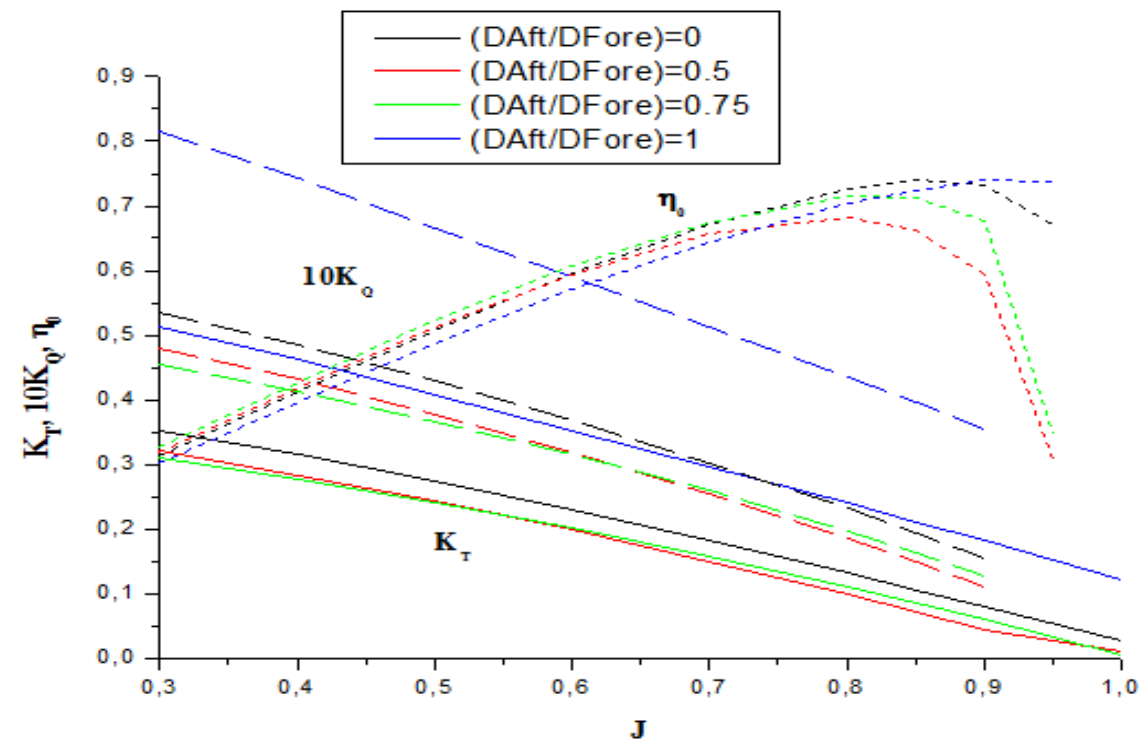

Fig. 12 Tandem hydrodynamic characteristics for different diameter ratios

\section{A- Tandem Aft propeller $\left(\mathrm{D}_{\mathrm{Aft}} / \mathrm{D}_{\text {Fore }}\right)=0.75$}
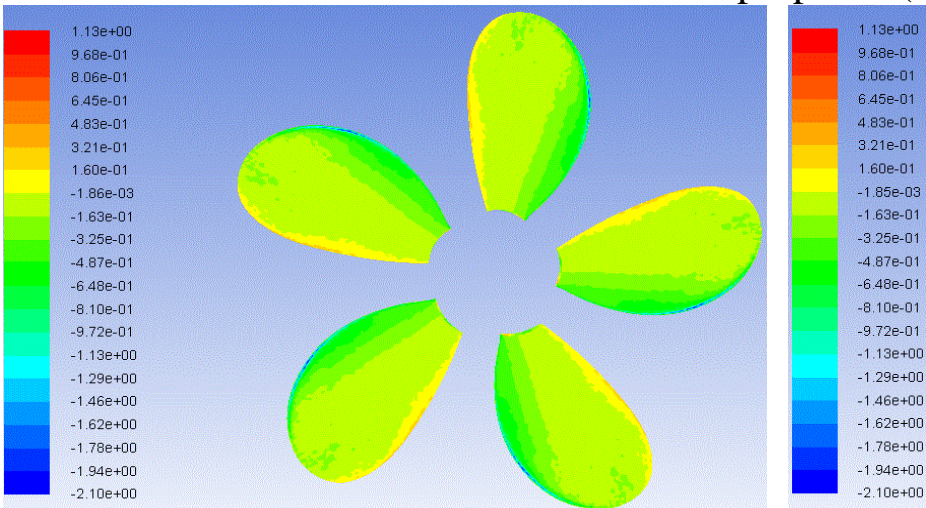

Face side

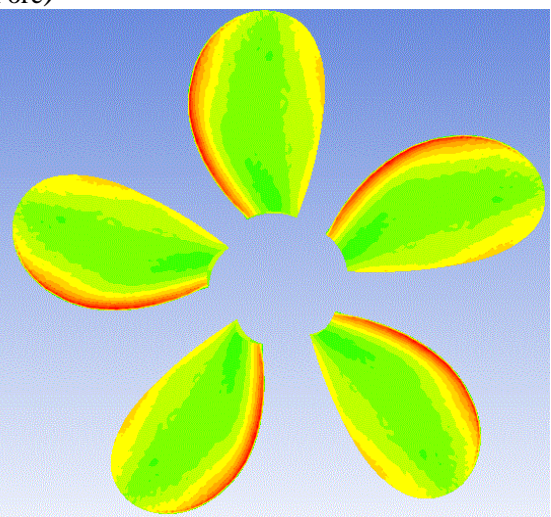

Back side 


\section{B- $\quad$ Tandem Aft propeller $\left(\mathrm{D}_{\text {Aft }} / \mathrm{D}_{\text {Fore }}\right)=0.5$}

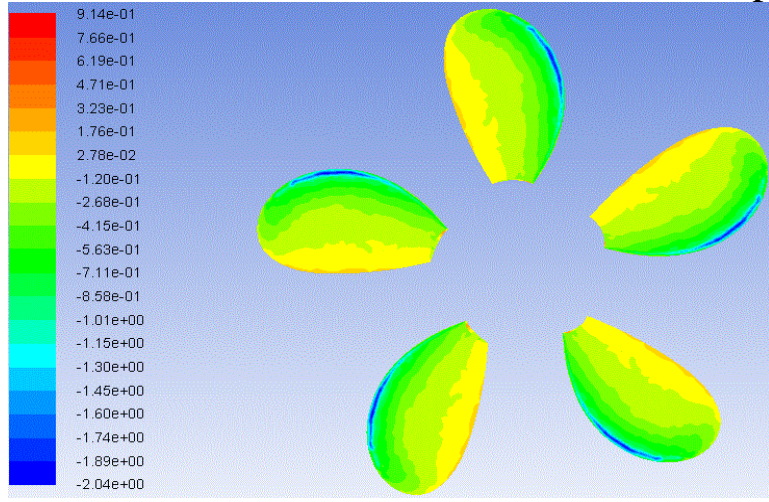

Face side

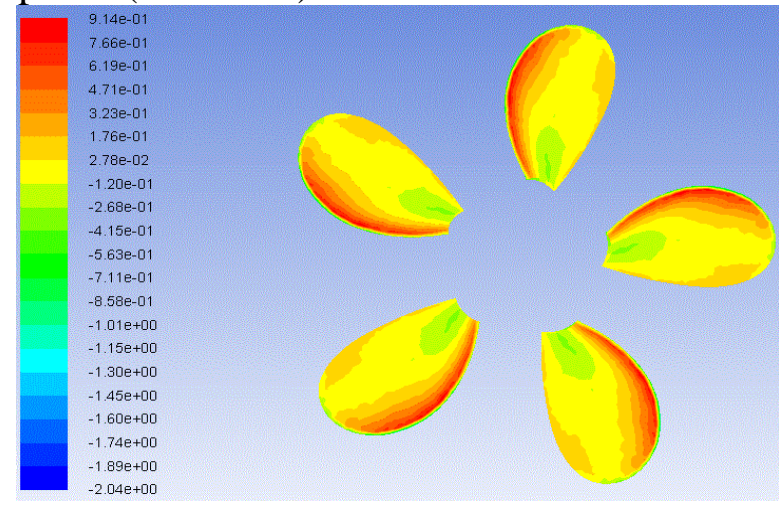

Back side

Fig. 13 Distribution of pressure coefficient contours for tandem aft propeller with different diameter ratios

Amongst the results obtained by the numerical simulation, the minimum pressure coefficient recorded on the configuration blades tested is also an important data on the flow around propellers mainly for the prediction of cavitation occurrence. Table 9 summarizes, at $\mathrm{J}=0.9$, the values of $\mathrm{Cp}_{\min }$ for the tested cases: single propeller, tandem propeller with $\mathrm{L} / \mathrm{D}=0.6$, tandem with different propeller diameters. This coefficient is calculated by considering the tangential velocity $(\mathrm{nD})$ as a reference. It appears clearly that the interaction between propellers in the tandem configuration causes a decrease of $\mathrm{Cp}_{\min }$ on both propellers compared to the single propeller. However, the numerical results reveal also that the minimum value of $\mathrm{Cp}_{\min }$ and its localization on either one or both tandem propellers depends on the tested advance coefficients as it can be seen in the Table 10. Indeed, for $\mathrm{J}=0.85$ and $\mathrm{J}=0.9$, the cavitation inception could appear firstly in the aft propeller where the absolute value of $\mathrm{Cp}_{\min }$ is higher. While it would occur in the fore propeller for $\mathrm{J}=1$ and $\mathrm{J}=1.1$. In this context, it is reported in [9] that the most serious cavitation occurred on the fore propeller and the extent cavitation area is greater on this propeller than on the aft propeller.

Table 9 Pressure coefficient values on aft and fore propeller at $\mathrm{J}=0.9$

\begin{tabular}{|c|c|c|}
\hline \multirow{2}{*}{ Propeller } & \multicolumn{2}{|c|}{$C p_{\min }$} \\
\hline & Fore & Aft \\
\hline Single & \multicolumn{2}{|c|}{-0.638} \\
\hline Tandem $\left(D_{\text {Aft }} / D_{\text {Fore }}\right)=1$ & -0.736 & -2.00 \\
\hline Tandem $\left(D_{\text {Aft }} / D_{\text {Fore }}\right)=0.75$ & -0.734 & -2.11 \\
\hline Tandem $\left(D_{\text {Aft }} / D_{\text {Fore }}\right)=0.5$ & -0.715 & -2.04 \\
\hline
\end{tabular}

Table $10 \mathrm{Cp}_{\min }$ values on the aft and fore propeller for different axial displacement and different $\mathbf{J}$

\begin{tabular}{|l|l|l|l|l|l|l|l|l|l|l|}
\hline L/D & \multicolumn{2}{|c|}{$\mathbf{0 . 2}$} & \multicolumn{2}{c|}{ 0.4 } & \multicolumn{2}{c|}{ 0.6 } & \multicolumn{2}{c|}{$\mathbf{0 . 7}$} & \multicolumn{2}{c|}{$\mathbf{0 . 8}$} \\
\hline J & Fore & Aft & Fore & Aft & Fore & Aft & Fore & Aft & Fore & Aft \\
\hline $\mathbf{0 . 8 5}$ & -0.716 & -2.39 & -0.792 & -2.46 & -0.794 & -2.27 & -0.82 & -2.33 & -0.856 & -2.26 \\
\hline $\mathbf{0 . 9}$ & -0.699 & -2.07 & -0.721 & -2.12 & -0.736 & -2.00 & -0.729 & -2.0 & -0.647 & -1.97 \\
\hline $\mathbf{1}$ & -2.01 & -1.59 & -1.66 & -1.39 & -1.68 & -1.32 & -1.64 & -1.30 & -1.75 & -1.29 \\
\hline $\mathbf{1 . 1}$ & -3.22 & -1.21 & -3.2 & -1.05 & -3.34 & -0.932 & -3.13 & -0.916 & -3.10 & -0.947 \\
\hline
\end{tabular}

Figures 14, 15 and 16 show the streamlines released by tandem propellers for the case $\mathrm{J}=0.9$ and ratios of diameter: $0.5,0.75$ and 1 . It can be clearly observed that the fore propeller path lines don't disturb those emitted by the aft propeller and the particles trajectories are 
regularly helical. However, it is noticed that the effect of the fore propeller path lines on the aft propeller depends on the diameters ratio. Indeed, the thrust coefficients calculated on the aft propeller are negative for the 0.75 and 0.5 configurations while it is positive for the third configuration as it is indicated above. Effectively, Figure 17 confirms that the contours of pressure on the aft propeller back side are noticeably different. In particular for the tandem $\left(\mathrm{D}_{\text {Aft }} / \mathrm{D}_{\text {Fore }}\right)=1$ where a depression zone on the upper part of the blade is observed giving a positive thrust. In fact, the fore propeller streamlines generate additional induced velocities on the aft propeller [9-17]. This effect causes locally an increase in the hydrodynamic pitch angle which would change the attack angle sign and therefore produce negative thrust.

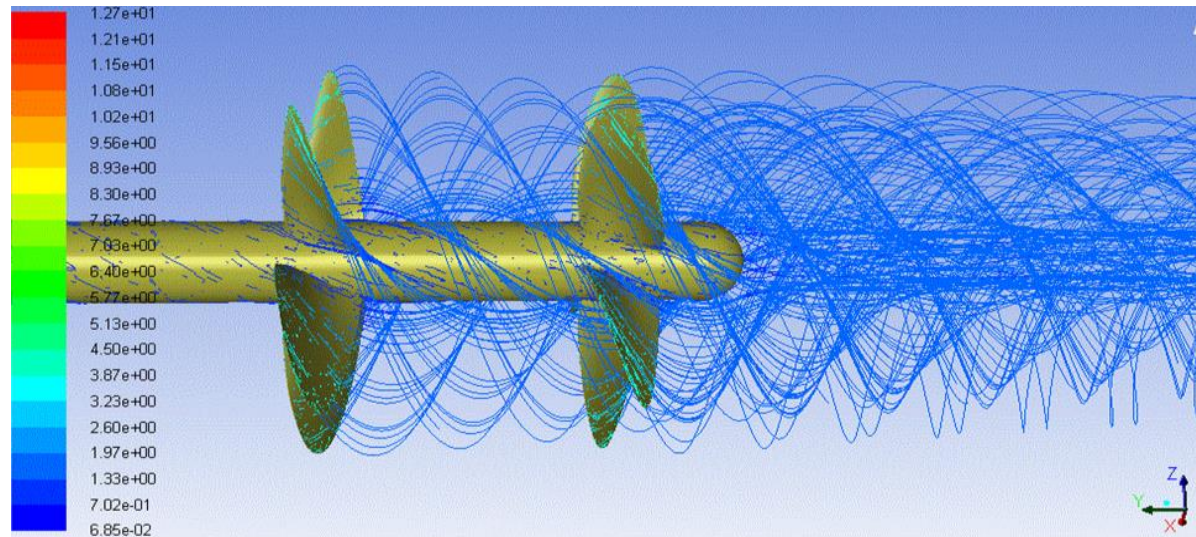

Fig. 14 Streamlines for tandem with $\left(D_{\text {Aft }} / D_{\text {Fore }}\right)=1$

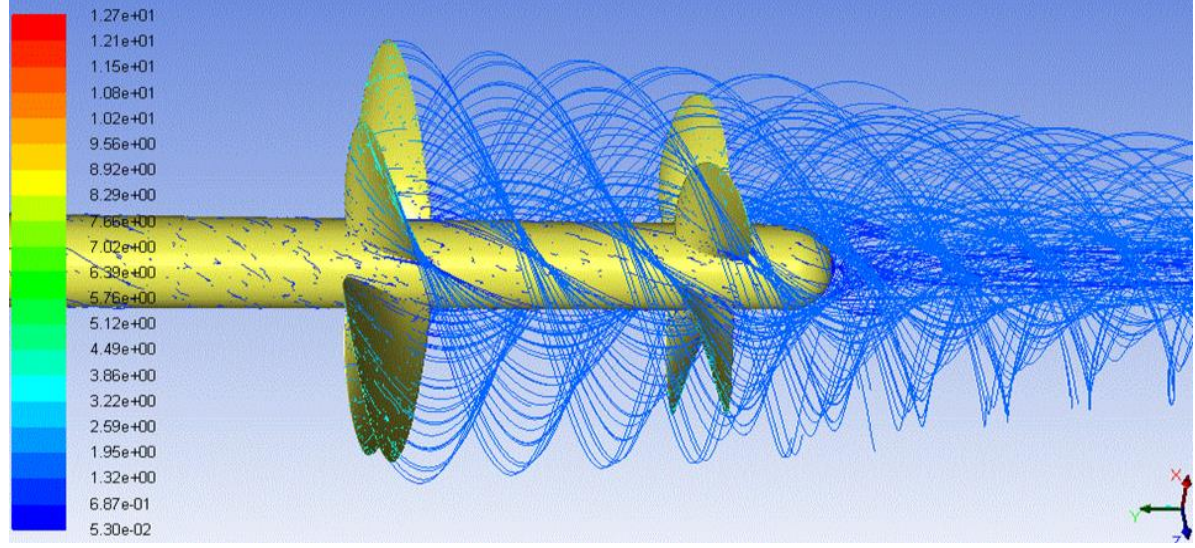

Fig. 15 Streamlines for tandem with $\left(D_{\text {Aft }} / D_{\text {Fore }}\right)=0.75$

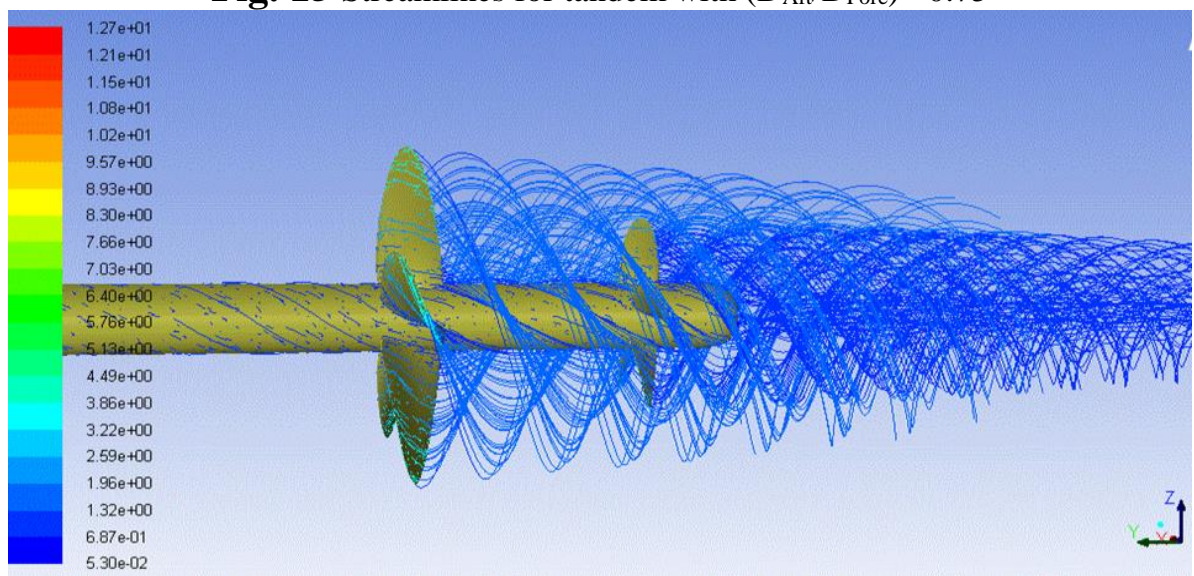

Fig. 16 Streamlines for tandem with $\left(\mathrm{D}_{\text {Aft }} / \mathrm{D}_{\text {Fore }}\right)=0.5$ 


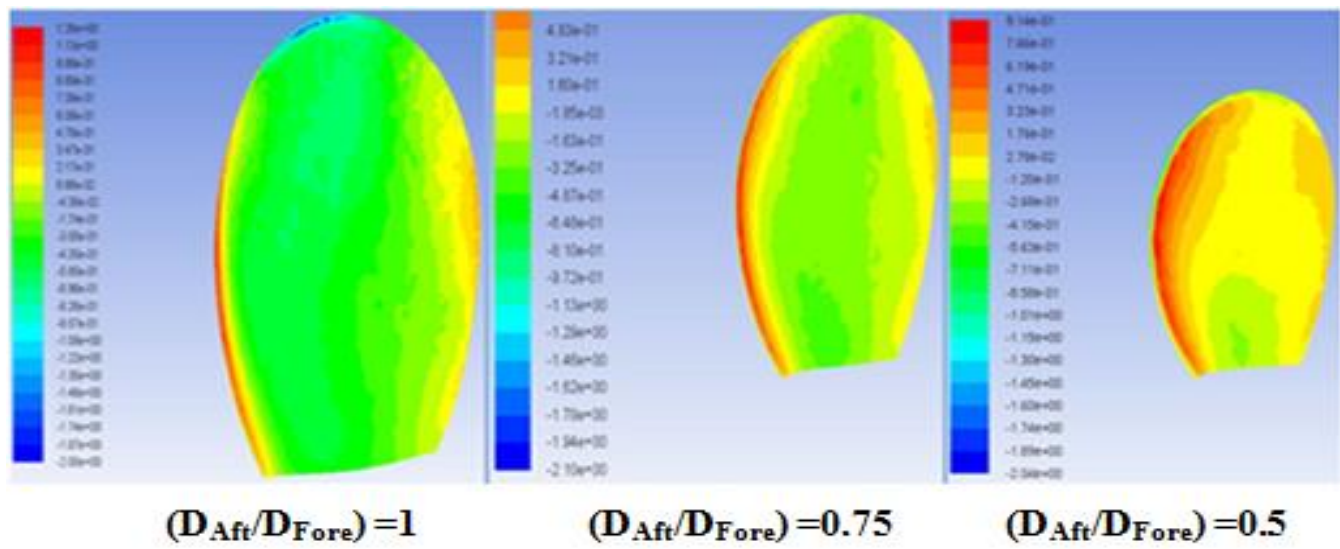

Fig. 17 Pressure contours on the aft propeller back side

\section{Conclusion}

In this work, numerical simulations have been carried out to study the tandem propellers hydrodynamic characteristics by using the commercial code Fluent. To investigate the effects of axial and angular displacement as well as the diameter ratio between the tandem propellers, several configurations have been tested. The values of axial displacement are extended to $0.8 \mathrm{D}$ comparatively to the previous researches. The numerical approach based on RANS methods has been successfully applied to validate the open water performances of the Seiun Maru propeller model. To constitute the tested configurations, the Seiun Maru propeller was used as basic geometry for the propellers mounted in tandem. Globally, the obtained results reveal the possibility to replace very loaded single propellers by tandem solution.

The most important result in this numerical simulation is the possibility to double the thrust and even more while ensuring a maximum efficiency. This indicates that for the same thrust the replacement of single propeller by tandem results in an appreciate diameter decrease. The study of axial and angular displacement effects between fore and aft propellers with identical diameters shows that the tandem geometry corresponding to $L / D=0.6$ is the best configuration among the tested geometries.

This investigation reveals also that the angular displacement has a little effect on the tandem hydrodynamic characteristics contrarily to the other studies. This is probably due to the large axial displacement values adopted in this study.

Furthermore, for the adopted tandem propeller pitch values, the tandem diameter ratio less than the unity provide a fall of the performances compared to single propeller and it does not give any practical interest. Therefore the use of tandem with idem diameters is strongly recommended to assure more advantages.

For the high efficiency values and contrarily to the experimental observations, the numerical simulation shows that the occurrence of cavitation on one or both tandem propellers depends on the tested advance coefficients.

Although the present study constitutes an exploratory investigation, nevertheless it shows the importance of tandem as an alternative solution to ameliorate the propulsion performance in ship building. However, it is necessary to insist on the fact that more investigations are needed to find out the optimum conditions for exploiting suitably tandem propellers. Indeed, experimental tests are indispensable to check the founded results especially for large axial displacement between the tandem propellers. It is also important to study the effect of some parameters such as: blades number, rake and skew variation on the tandem hydrodynamic characteristics. Finally, some researches should be devoted to the cavitation problem on highly loaded tandem in order to define its limits of use. 


\section{Nomenclature}

$\begin{array}{ll}\mathrm{D} & \text { Propeller diameter } \\ \mathrm{Z} & \text { Blade number } \\ \mathrm{P} / \mathrm{D} & \text { Propeller pitch ratio } \\ \mathrm{L} / \mathrm{D} & \text { Relative axial displacement } \\ \theta & \text { Relative angular position } \\ \mathrm{D}_{\text {Fore }} / \mathrm{D}_{\mathrm{Aft}} & \text { Diameter ratio } \\ \mathrm{C}_{\text {Pmin }} & \text { Pressure coefficient } \\ \mathrm{n} & \text { Number of propeller revolutions } \\ \mathrm{V}_{\mathrm{a}}, \mathrm{J} & \text { Propeller advance velocity, Advance coefficient } \\ \mathrm{T}, \mathrm{Q} & \text { Thrust, Torque, } \\ \mathrm{K}_{\mathrm{TTotal}} & \text { Total thrust coefficient } \\ \mathrm{K}_{\mathrm{QTotal}} & \text { Total torque coefficient } \\ \eta_{0} & \text { Propeller efficiency in open water }\end{array}$

\section{REFERENCES}

[1] Carlton, J., 2007. "Marine Propeller and Propulsion”. 2nd Edition Great Britain, MPG Books Ltd, Bodmin Cornwall.

[2] Beveridge, J.L., 1976. "Calculation of Optimum Efficiency for a Series of Large-Hub Propellers for Application to Tandem Propulsion of a Submerged Body of Revolution". Report of Hydrodynamics Laboratory.

[3] BRESLIN, J.P., ANDERSAN, P., 1994. "Hydrodynamics of ships propellers". Conbridge Ocean Technology, Series 3, 130-138.

[4] Molland, F., Turnock, R., Hudson Frontmatter, A., 2011. "Ship Resistance and Propulsion: Practical Estimation of Ship Propulsive Power". 249-250.

[5] Perez-Gomez, G., Gonzillez-Adalld, J., 1994. "Contra-rotating and Tandem CLT Propellers". Transaction of SNAME, No. 06, 06-37.

[6] Rice, R.S., Wilson, W.G., 1964. "Equipment Design for a Tandem Propeller Submarine Free-running Model”. AD 607493, Cornell Aeronautical Laboratory, Buffalo, New York.

[7] Liang, C., Ming, Z., Genlu, W., 2003. "Experimental Investigations on the Hydrodynamic Performance of Podded Propulsion". Report of Shanghai JIAOTONG University, (in Chinese).

[8] Xiong, Z. Z., Super, Y., 2016. "Hydrodynamic Performance Based on CFD for Scale Podded Propeller Type”. Ship Science and Technology, Vol. 5, (in Chinese).

[9] Qin, S., Yunde, G., 1991. "Tandem Propellers for High Powered Ships”. Transaction of RINA, 347-362.

[10] Qin, S., Yunde, G., Shuzhen, Z., 1979. "On the Open Water Series Test of Model Tandem Propeller and its Design Method with Charts". Journal of Shipbuilding of China, No. 66, (in Chinese).

[11] Shamsi, R., Ghassemi, H., 2013. "Numerical Investigation of Yaw Angle Effects on Propulsive Characteristics of Podded Propulsors". Int. J. Naval Archit. Ocean Eng., Vol.5, 287-301. https://doi.org/10.2478/IJNAOE-2013-0133.

[12] Cheng, M., Du, D., Zheng-fang, Q., Chen-jun, Y., Cheng, K., 2003. “A Potential Method for Steady and Unsteady Hydrodynamic Performance Computation of Podded Propulsors". SHANGHAI JIAOTONG University, Shanghai, China.

[13] Krasilnikov, V., Sileo, L., Steinsvik, K., 2016. "Computational Analysis of Scale Effect on the Performance Prediction for Modern Offshore Vessels”. STAR Global Conference, (March 7-9), Prague.

[14] Wei, H., Keqiang, C., Plums, A., 2015. "Experimental Study on the Status of the Hydrodynamic Propulsion Pod Steering Tandem”. Report of HUAZHONG University of Science and Technology (Natural Science), (in Chinese).

[15] Koronowicz, T., Krzemianowshi, Z., Tuszkowska, T., Szantyr, J.A., 2010. “A Complete Design of Tandem Co-rotating Propellers using the New Computer System”. Polish Maritime Research, 4(67), Vol. $17,17-25$. 
[16] Koronowicz, T., Krzemianowshi, Z., Tuszkowska, T., Szantyr, J.A., 2010. “A Complete Design of Contra-rotating Propellers using the New Computer System”. Polish Maritime Research, 1(64), Vol. 17, 14-24.

[17] Refayet Ullah, M., 2010. "A Theoretical Method for the Design of Marine Tandem Propellers". Proceedings of MARTEC 2010, (11-12 December 2010), BUET, Dhaka, Bangladesh, 477-482.

[18] Qin, S., yunde, G., Shuzhen, Z., 1980. “A Simplified Theoretical Method for Calculating Tandem Propellers". Journal of Shipbuilding of China, No. 71, (in Chinese).

[19] Shen, H., Yuan, S.S., Guomin, C., 1983. "Number of High-altitude High Speed and High Efficiency Bulbs Propeller System”. Ship Engineering, Vol. 2, (in Chinese).

[20] Wang, A., Li, C., Qiaoyue, X., 2016. "Numerical Prediction of Tandem Propeller Hydrodynamic Performance". Ship Science and Technology, (in Chinese).

[21] Junying, B., 2013. "Preliminary Design Study on Multi-propeller". Report of DALIAN University of Technology, (in Chinese).

[22] Month, C.J., 2015. “CFD Study on Open Water Performance of Tandem Propeller”. SHIP XIANGTAN University, (in Chinese).

[23] Xun, H., Chao, W., Sheng, H., 2014. “Application Panel Method in Tandem Propeller Hydrodynamic Performance". WUHAN University of Technology (Transportation Science \& Engineering Edition), (in Chinese).

[24] Nakisa, M., Abbasi, M.J., Amini, A.M., 2010. “Assessment of Marine Propeller Hydrodynamic Performance in Open Water via CFD”. Proceedings of MARTEC 2010, (11-12 December 2010), BUET, Dhaka, Bangladesh, 35-43.

[25] Guangyu, Z., Ke, C., Cheng, M., Haopeng, C., Masayoshi, M., 2013. "CFD Prediction Method of Hydrodynamic Performance Podded Propulsion in Unsteady Flow”. Proceeding of Ship Hydrodynamics Conference, (in Chinese).

[26] Junming, H., Li, L., Yan, L., Xin, Y., 2015. "B Series Tandem Propeller Open Water Performance Parameters Matching Numerical Simulation”. China Ship Research, Vol.5, (in Chinese).

[27] Funeno, I., 2002. "On Viscous Flow around Marine Propellers-Hub Vortex and Scale Effect". Proceedings of New-S-Tech, Third Conference for New Ship and Marine Technology, 17-26.

[28] Ekinci, S., Çelik, F., Arikan, Y., 2011. "Investigation of the Influence of Skew and Rake into the Propeller". INT-NAM 2011, $1^{\text {st }}$ International Symposium on Naval Architecture and Maritime, (2-25 October 2011), Istanbul, Turkey, 417-423.

[29] Watanabe, T., Kawamura, T., Takekoshi, Y., Maeda, M., Rhee, S.H., 2003. "Simulation of Steady and Unsteady Cavitation on a Marine Propeller Using a RANS CFD Code”. Fifth International Symposium on Cavitation (CAV2003), Osaka, Japan, 1-4.

[30] Wilcox, D.C., 1998. “Turbulence Modelling for CFD”. 2nd ED., DCW Industries, Inc., Canada.

[31] Ukon, Y., Kudo, T., Kamiriisa, H., Yuasa, H., 1991. "Measurement of Pressure Distribution of Full Scale Propellers". Proceeding of Propellers/Shafting'91, SNAME, Virginia Beach, (September 17-18), No.13, $1-15$.

[32] Sipilä, T., Siikonen, T., Saisto, L., Martio, J., Reksoprodjo, H., 2009. “Cavitating Propeller Flows Predicted by RANS Solver with Structured Grid and Small Reynolds Number Turbulence Model Approach". Proceeding of the $7^{\text {th }}$ International Symposium on Cavitation (CAV2009), Ann Arbor, Michigan, USA, 1-11.

[33] Kimura, K., Kawamura, T., Fujili, A., Taketani, T., Huang, Z., 2009. "Study on Unsteady Cavitation Flow Simulation around Marine Propeller using a RANS CFD code". Proceeding of the 7th International Symposium on Cavitation (CAV2009), No. 68, (17-22 August), Ann Arbor, Michigan, USA.

[34] Xiong, Y., Wang, Z., Qi, W., 2013. "Numerical Study on the Influence of Boss Cap Fins on Efficiency of Controllable-pitch Propeller". Journal of Marine Science and Application, 13-20. https://doi.org/10.1007/s11804-013-1166-9.

[35] Masaju, I., Hongbin, Y., 2013. "Development and Performance Estimates of a Ducted Tandem CRP”. Third International Symposium on Marine Propulsors smp'13, (May 2013), Tasmania, Australia.

Submitted: $\quad 31.07 .2016$ Accepted: 04.12 .2016 .
Boucetta Djahida, djahida.boucetta@yahoo.fr Imine Omar

Department of marine engineering, Faculty of mechanical engineering, University of Sciences and Technology of Oran, USTO, Oran, Algeria 